\title{
IS THERE AN INNATE NEED FOR CHILDREN?
}

\author{
Ruut Veenhoven
}

Published in: European Journal of Social Psychology, 1975, vol 1 pp 495-501

\section{Introduction}

The public debate on population policy is still going on, only the topics have changed during the last decades. Yesterday we discussed the point as to whether contraception were morally acceptable. Today we have almost finished the discussion about legalization of abortion. Tomorrow we will probably talk about the political instruments to realize zero-population growth, i.e., governmental promotion of voluntary childlessness and sterilization. In this debate assumptions about human motives for. having children play an important role. Many objections against an active government policy to reduce population growth are rooted in the belief that all human beings have an inner urge to have children, an urge which cannot be curtailed. Any pressure to limit procreation is assumed to lead people away from this innate destination and to make them feel empty and unhappy.

This is a widespread belief. It shapes attitudes towards childless couples, abortion and contraception, not only with the man in the street, but also in the minds of legislators, politicians, doctors and family counselors. It is expressed in many forms: in the romantic descriptions of motherhood, in the pity we feel for childless couples, in our value-orientation towards family, marriage and divorce. etc. This belief is also reflected in the common saying that people who have no children do not realize what they are missing. They are assumed to be unaware of the fact that they gain less satisfaction from life than parents do.

This belief lives in the social sciences as well. When a particular kind of behavior is distributed ubiquitously in human societies, there is a tendency for social scientists to attribute the cause of that behavior not to social learning but to human nature itself. So in trying to account for the phenomenon that all over the world most married persons become parents, some theorists postulated the existence of a reproductive drive. Kephart (1966, pp. 14-46) hypothesizes a 'parental impulse'. A 'maternal instinct' is postulated by Deutsch (1945, pp. 12-14), Soddy (1964, pp. 43-44) and Wengraf (1953, p. 195). Benedek (1959) speculates that there is a 'drive toward fatherliness'. In the present article this belief will be analyzed more closely and its tenability will be examined.

\section{The instinct theory of human procreation}

This popular belief can be formulated as a theory consisting of seven propositions.

1. All species of animals have an innate urge to create offspring. If not they would have died out.

2. As a result, all normal adult human beings feel the inner need to bring forth children them-selves.

3. This need is a fundamental one which cannot be denied to the organism without injury. One cannot violate one's own nature with impunity. Lack of fulfillment of this need cannot be compensated by other satisfactions,

4. As a result, the absence of children gives rise to feelings of unhappiness and/or psychosomatic disturbances.

5. These feelings and disturbances grow stronger as the state of childlessness becomes more definite. 
6. In old age they manifest themselves, e,g., in feelings of social isolation, fear of death and the idea that life has been useless.

7. This need for children is stronger in women than it is in men.

\section{$3 \quad$ Why this theory is wrong}

This theory seems plausible at first glance, but looking at it more closely we can see that it is based on simplifications and that its predictions turn out to be faulty. We will examine the propositions mentioned above successively.

\subsection{Animals have no 'desire for offspring'}

It is true that almost all animals produce offspring, but it is probably not true that this behavior is determined by an innate desire for offspring. It is highly improbable that animals are motivated by such conscious wishes for long-term effects. It is far more probable that the reproduction behavior is governed by more simple mechanisms. The most basic of these could be the sexual drive which is recognizable in all animals. In addition many animals are apt to display maternal behavior patterns when under influence of specific stimuli and/or hormones which are produced as a result of pregnancy and lactation. This behavior is not a permanent motivational characteristic of the animals concerned: It disappears when the production of hormones stops and can be reactivated by artificial administration of hormones. Some animals are outfitted with an inhibition against attacking the young of their own species; some species of apes even help young ones of other parents in case of danger.

These three mechanisms seem to function relatively independently of each other. They are governed by different factors. None of them seems to come forth from a conscious desire for offspring, but nevertheless they result in continuous procreation.

\subsection{Neither have human beings an innate need for children}

Contrary to animals, human beings are capable of pursuing conscious long-term goals. Many human beings are conscious of a desire for children and work to have them, but this behavior is not necessarily dictated by an innate need. Human behavior is seldom directly governed by instincts. Again and again the ever-present influence of environmental circumstances and learning has been demonstrated. It is improbable that they would not influence the procreation behavior. In addition human instincts are seldom linked to such specific patterns of behavior. As far as instinctual tendencies in human beings may be assumed they pertain to vague preferences which are manifested in very different forms of behavior. Reasoning along this line we could hypothesize that human beings have instinctual needs for security, love, esteem and meaningfulness (Maslow, 1964). These needs might be realized in parenthood as well as in a cloister life, in a political career as well as in an intimate interaction with friends, etc.

The specific form in which the individual chooses to realize his instinctual needs is probably highly affected by his experience and by the alternatives the socio-cultural environment offers him. It makes more sense to look at parenthood as one of these alternatives than to postulate an innate and compelling desire for children.

The idea of an instinctual desire for children is not only a theoretical simplification but also fails to meet empirical support. If there were such a built-in need the desire for children should be universal, but this prediction is not confirmed by facts. Millions of people decide spontaneously for voluntary childlessness. In Canada $5 \%$ of all married couples opt for childlessness (Veevers, 1973). In the Netherlands $15 \%$ of the couples married in the last few years intend to forego parenthood (NIDI, 1974). This is not a temporary modern whim, but a 
phenomenon that has also been observed in earlier times, In medieval Western European society, for example, a major part of the population remained childless.

These facts, however, offer no decisive evidence against the procreation-instinct theory. It could be agreed that all these childless people pay a heavy price for their choice, that the violation of such a compelling need makes people unhappy -- in any case less happy than people who follow this need. Here we arrive at propositions 4, 5 and 6 mentioned earlier. To test these propositions a secondary analysis was made of the data from an investigation concerning the health and the life circumstances among a representative sample of the adult population of the Netherlands, As we will see below these data give no support to the predictions of the procreation-instinct theory.

\subsubsection{Parents are not happier than non-parents}

All respondents rated their general feelings of happiness on a seven-point scale. Comparison of the scores of couples with children and of couples without children revealed no striking differences. Non-parents seem slightly happier, but the difference fails to meet the $95 \%$ level of significance (see Table 1).

One could object that this outcome is possibly influenced by a tendency of childless respondents to rate more happiness than they really feel. We checked this objection by testing the hypothesis that happy non-parents show a higher score on the General Index of Complaints (see below) than happy parents do. This check is based on the assumption that frustration of a fundamental human need gives rise to both feelings of unhappiness and psychosomatic disorders, the avowal of which is more susceptible to rationalizations by the respondent in the first case than in the latter. This control hypothesis was rejected; the happiness scores of non-parents turned out to be no less liable than those of the parents.

\subsubsection{Parents do not have fewer psychosomatic complaints than non-parents}

The same holds for psychosomatic complaints. The questionnaire contained 85 questions concerning various complaints such as headache. nervousness, frequent diarrhea, feelings of being unnatural, depression, etc. On the basis of these questions a General Index of Complaints was constructed which turned out to be highly related to the clinical diagnose of neurasthenia. This index was compared for parents and non-parents, but a statistical relationship could not be demonstrated.

\subsubsection{Parents feel less healthy than non-parents do}

The questionnaire also contained a rating scale for subjective health feeling. Contrary to the predictions of the procreation-instinct theory parents turn out to feel less healthy than non-parents (see Table 1). More than the fulfillment of an undeniable need, parenthood seems to be a tiring job.

\subsubsection{Non-parents do not face a poorer life when growing older}

The relation between childlessness and happiness is not affected by age. The same holds for the relationship between childlessness and psychosomatic complaints. Age does affect the relation with subjective health feeling: Non-parents in the age of 55 to 65 are feeling significantly better than parents. 


\subsubsection{Non-parents report no more doubts about the meaning of their life than parents}

Analysis of the answers to a question about the meaningfulness of one's life did not reveal a difference between parents and non-parents. No relationship could be found within the different age groups, nor could a stronger tendency towards such a relation be demonstrated in the older age groups.

The same holds for anxiety about old age and death. Non-parents do not seem to expect a more problematic and lonesome end of their life. On the contrary, older parents report more feelings of anxiety concerning this subject, though the difference hardly reaches the $95 \%$ level of significance. There is no evidence for the notion that non-parents feel more isolated in the later years of life. Neither do non-parents report a lower degree of marital happiness nor show a higher degree of problems in social interaction.

\subsubsection{Procreation-instinct theory is applicable neither to men nor to women}

On the basis of folk theory we might suppose that the results mentioned above hide a major difference between men and women, with women being especially prone to negative effects of childlessness. This hypothesis was tested, but it received little support. Childless married women revealed no less happiness than mothers and reported neither more psychosomatic complaints. nor more doubt about meaning of life. Likewise they reported neither less subjective health feeling, nor more anxiety about old age and dying. They did not report less marital satisfaction. In all age groups a tendency for non-parents to report a higher state of well-being could be observed, but none of them reached the $95 \%$ level of significance. For men they did in two instances, Married male non-parents feel more healthy and report a higher level of marital satisfaction.

Finally we might suppose in the basis of the procreation-instinct theory that pregnant married women are happier than non-pregnant married women. pregnancy being at least partial gratification of the maternal urge. Twenty-two married respondents were pregnant at the time of the interview. They were less happy than non-pregnant married female respondents. This result fits in with the findings of Klein et al. (1950) and Tobin (1957). Again, a derivation from the procreation-instinct theory fails to find empirical support. 


\section{REFERENCES}

Aakster, C. W. (1972)

Socio-cultural variables in the etiology of health disturbances

University of Groningen, The Netherlands.

Benedek, T. (1959)

Parenthood as a developmental phase.

J. Amer. Psychoan, Assoc., 7, 389-417.

Deutsch, H. (1945)

The psychology of women

Vol. 2: Motherhood, New York, Grune \& Stratton.

Klein, H.R. Potter, H.W. and Dyk, R.B. (1950)

Anxiety in pregnancy and child birth

New York, Hoeber.

Kephart, W (1966)

The family, society and the individual

New York, Houghton Mifflin.

Maslow, A. H., (1954)

Motivation and personality

New York, Harper \& Row.

NIDI (1974)

Demography, Bulletin of the Netherlands Inter-university

Demo graphic Institute, No. 7, The Hague.

Soddy, K. (1964)

The unwanted child

J. fam. Welf, 11, 39-52.

Tobin, S, M. (1957)

Emotional depression during pregnancy

Obstet. Gyn., 10, 677-681.

Veevers, J. E. (1973)

Voluntary childless wives: An exploratory study

Soc. sc. Res., 27, 356-366.

Wengraf, F. (1953)

Psychosomatic approach to gynaecology and obstetrics Springfield, 111., Thomas. 
Table 1.

Association of childlessness with various indicators of well-being in different age groups; married subjects in a representative sample (1500) of the 25-65 year old population of the Netherlands

\begin{tabular}{|c|c|c|c|c|c|c|c|c|c|c|c|c|}
\hline Age & \multicolumn{2}{|c|}{ Happiness } & \multicolumn{2}{|c|}{$\begin{array}{c}\text { Psychosomatic } \\
\text { complaints }\end{array}$} & \multicolumn{2}{|c|}{$\begin{array}{l}\text { Feeling of } \\
\text { health }\end{array}$} & \multicolumn{2}{|c|}{$\begin{array}{l}\text { Lack of } \\
\text { meaning }\end{array}$} & \multicolumn{2}{|c|}{$\begin{array}{c}\text { Anxiety about } \\
\text { old age and } \\
\text { health } \\
\text { gamma interval }\end{array}$} & $\begin{array}{l}\text { Problems in } \\
\text { social } \\
\text { interaction } \\
\text { gamma interval }\end{array}$ & $N$ \\
\hline & & & & & & & & & & & & \\
\hline $25-29$ & $\odot .093$ & 0.393 & $\odot .095$ & $\odot .245$ & $\odot .099$ & 0.383 & $\odot .050$ & 0.452 & $\odot .020$ & $\odot .277$ & $0.115 \quad 0.261$ & 180 \\
\hline $30-34$ & 0.263 & 0.572 & 0.175 & 0.454 & 0.150 & 0.611 & $\odot .198$ & 0.698 & 0.178 & 0.355 & $0.060 \quad 0.467$ & 194 \\
\hline $35-39$ & $0.604^{*}$ & 0.459 & 0.115 & 0.410 & 0.394 & 0.622 & 0.048 & 0.501 & 0.063 & 0.393 & $0.135 \quad 0.430$ & 205 \\
\hline $40-44$ & 0.228 & 0.400 & 0.107 & 0.301 & 0.093 & 0.388 & 0.104 & 0.430 & 0.145 & 0.402 & $0.024 \quad 0.389$ & 223 \\
\hline $45-49$ & 0.011 & 0.563 & 0.027 & 0.510 & 0.011 & 0.645 & 0.135 & 0.608 & 0.123 & 0.630 & $0.228 \quad 0.454$ & 190 \\
\hline $50-54$ & 0.080 & 0.317 & 0.007 & 0.318 & 0.210 & 0.367 & 0.050 & 0.452 & 0.023 & 0.297 & $0.026 \quad 0.353$ & 152 \\
\hline $55-59$ & 0.476 & 0.550 & 0.297 & 0.462 & $0.652 *$ & 0.564 & 0.191 & 0.561 & $0.510 *$ & 0.497 & $0.451 \quad 0.474$ & 118 \\
\hline $60-65$ & 0.200 & 0.474 & 0.302 & 0.391 & $0.644^{*}$ & 0.435 & 0.189 & 0.576 & 0.282 & 0.339 & 0.0620 .434 & 114 \\
\hline & & & & & & & & & & & & \\
\hline total & 0.123 & 0.160 & 0.075 & 0.126 & $0.225^{*}$ & 0.171 & 0.012 & 0.183 & 0.040 & 0.132 & $0.045 \quad 0.138$ & 1376 \\
\hline
\end{tabular}

1. Gamma varies from -1 to +1 :Positive gamma indicates more well-being for non-parents than for parents.

2 95\% asymptotic confidence interval.

* Significant at the $95 \%$ level of confidence. 